\title{
On Individuation and Constitutive Activity: A View From the Philosophy of Gilbert Simondon and the Phenomenology ${ }^{1}$
}

\section{Sobre la individuación y la actividad constitutiva: una visión desde la filosofía de Gilbert Simondon y la fenomenología}

\author{
María Clara Garavitoº \\ Universidad Nacional de Colombia
}

DOI: 10.17533/udea.rp.v10n1a06

Recibido: 2017-12-13 Aceptado: 2018-02-17

Para citar este articulo en APA: Garavito, M. (2018). On Individuation and Constitutive Activity: a View From the Philosophy of Gilbert Simondon and the Phenomenology. Revista de Psicología Universidad de Antioquia, 10 (1), 143-169. DOI: 10.17533/udea.rp.v10n1a06

\begin{abstract}
According to Simondon (2009; 2013), individuation is a phenomenon of differentiation and integration that occurs in all kinds of individuals, from the non-biological to collective ones. However, each level of individuation includes different challenges, depending on the complexity of the relations with the surroundings. In the psychical, the individuation process deals with relationships between consciousness and the materiality. I connect Simondon's interest in understanding psychical life through individuation with a more phenomenological concern for understanding consciousness as a phenomenon of a lived body: here, what Simondon calls subconsciousness offers the connection between phenomenology and individuation. In phenomenological terms, subconsciousness is connected to the pre-reflective level of consciousness through animation (namely the kinetic/kinesthetic, sensorial, affective and emotional manifestations of the living).
\end{abstract}

KeyWords: psychicalindividuation, subconsciousness, pre-reflectivity, lived body, animation.
Resumen: Según Simondon (2009; 2013), la individuación es un fenómeno de integración y diferenciación que ocurre en todo tipo de individuos, desde individuos no biológicos hasta individuos colectivos. Sin embargo, cada nivel de individuación incluye diferentes desafíos según la complejidad de la relación del individuo con el entorno. En lo psíquico, el proceso de individuación se ocupa de las relaciones entre la conciencia y la materialidad, Conecto el interés de Simondon por comprender la vida psíquica a través de la individuación con una preocupación más fenomenológica de entender la conciencia como un fenómeno del cuerpo vivido: lo que Simondon llama subconsciencia aquí ofrece una conexión entre la fenomenología y la individuación. En términos fenomenológicos, la subconsciencia podría ser entendida como conectada al nivel pre-reflexivo de la conciencia a través de la animación; es decir, las manifestaciones cinético/cinestésicas, sensoriales, afectivas y emocionales de los seres vivos.

Palabras Clave: individuación psíquica, subconsciencia, pre-reflexividad, cuerpo vivido, animación.

1 Artículo derivado de la investigación "Co-constitution as the Primal Experience of Others: Ideas from Phenomenology of Emotions”, realizada en la University of Exeter, UK, con la tutoría de la Doctora Giovanna Collombetti.

2 Psicóloga, Magíster en Filosofía. Candidata a Doctora en Filosofía, Universidad Nacional de Colombia, bajo la modalidad de Beca Doctorado Nacional Colciencias. Correo electrónico: mcgaravitog@ unal.edu.co; https://orcid.org/0000-0002-5185-6824 


\section{Introduction}

Gilbert Simondon $(2009 ; 2013)$ is the most representative contemporary author on the problem of individuation. According to him, individuation is a phenomenon of integration and differentiation in relation to alterity that occurs in all kinds of individuals, from the non-biological (such as a crystal which is a minimal form of individuation resulting from chemical reactions) to collective individuals (such as a society which is a complex form of individuation resulting from interactions of psychological individuals). He posited that there is a continuum of different levels of individuation, all according to an intrinsic principle that characterizes all of them: transduction, understood as a principle of organization and reorganization of individuals in increasing levels of complexity, in accordance to the relationship between individuals and between them and their surroundings. Therefore, even though there is a continuum in rising levels of individuation, each level includes different challenges depending on the complexity of those relationships.

The idea of individuation as a phenomenon occurring in different levels of complexity puts Simondon in relation with authors who, from different perspectives, considered individuation from biological forms, like Maturana and Varela (1994) and psychical forms, like Piaget (1965). Mainly, the focus in the psychical brings the problem of consciousness, and especially the role of the body in the first-person perspective. I found here in Simondon a match with a phenomenological concern, for instance in Merleau-Ponty (2012) of getting away from an idealism and a solipsism in the conscious experience: a concern for finding in the body, the world; and in others the key for the constitution of an inner life.

The purpose of this paper is to connect Simondon with a phenomenological perspective on the emergence of self-awareness in the continuous dialectic experience of integration and differentiation. The main idea of this paper is to posit, through the phenomena of individuation, a world and a self are given to an embodied consciousness; therefore, having an experienced self -initially as an experience of a bodily self- would be the result of individuation occurring 
in what Simondon called a subconscious experience as the core of psychical individuation (Simondon, 2013, p. 242).

To Simondon, subconsciousness is understood as a level of psychism that is placed between the conscious and the unconscious experiences; it is understood as the region of affectivity and emotionality (Simondon, 2013, p. 242). That level of affectivity and emotionality functions as a sort of bridge between the other two levels: thanks to subconscious experience, consciousness is a manifestation of the relation between body and world, and action as a bodily manifestation is not a mere sequence of unintentional movements but a conscious experience.

Through that conceptualization of subconsciousness I found some elements to understand Simondon's ideas in a phenomenological view. For instance, it is possible to find some relationship between that subconscious experience and a pre-reflective experience as is understood in phenomenology (cf. Merleau-Ponty,1968). Namely, even though subconsciousness in Simondon is not understood quite as a conscious structure (as distinct from a pre-reflective experience, which is conscious) (Merleau-Ponty, 1968, p. 52), I find the relation between body and consciousness through affective and emotion experiences - the role of the subconscious level in Simondon- very similar to the pre-reflective consciousness of phenomenology: pre-reflective experience, as an implicit, tacit level of the experience, in which the lived body is constituted while navigating the world, links the givenness of a world to a consciousness with its more basic roots in the constitution of a lived body.

Ultimately, this reading of subconsciousness in Simondon as sharing elements with a pre-reflective level of consciousness connects Simondon to a more constructive phenomenology, as it is understood by Sheets-Johnstone (2011): that connection between body and consciousness through affection and emotion makes us return to the primal experiences in which we initially had experiences of the world. And, since individuation is an ontogenetic process, Simondon's perspective is in accordance with a constructive phenomenology which looks into the historical nature of phenomenal life (cf. Sheets-Johnstone, 2011); therefore, a subject can be traceable through the history of the individual. 


\section{Individuation and the constituted world}

\section{The basic individuation in living beings}

In Simondon, the world is not occupied by materially-defined entities: neither inorganic nor organic identities depend on their materiality but on the process of individuation, by which that materiality is altered and organized to integrate and differentiate itself (Simondon, 2013). However, an individual is not that process of individuation nor is it the relations among the parts; the individual appears in the stability of the relations: it is a metastability (2013, p. 26).

Initially, metastability means an equilibrium that is more a dynamic than a static property; in thermodynamic terms, an individual is the product of a homeostatic process, dealing with entropy for maintaining a particular structural configuration. Individuation (as Simondon named the preindividual) explains the emergence of individuals through a coupling of the pre-organization with the environment and the transmission of information through transduction. Transduction, in these regards is "an operation -physical, biological, mental, social- by which an activity propagates itself from one element to the next, within a given domain, and founds this propagation on a structuration of the domain that is realized from place to place (...)" (Simondon, 2009, p, 11). In transduction, a way of structuration (therefore, some equilibrium) is replicated in different dimensions across the organization or across organizations, from non-living to living entities. The system's identity is in the transduction itself; it is what is propagated.

What is propagated through transduction is information. Thus information is which is shared and which is relative to different levels of individuation. In Simondon, information is not composed of fixed transmitted units: information is relative to continuous changes in the individuation that depend, among other reasons, on the way in which the environment appears. For instance, visual information is relative to a relationship between an agent and its environment, which includes some affective experiences that affect the way of acting. 
Simondon could be considered as a systems thinker who would agree with many of Bertalanffy's ideas (1968). He is also close to more biological and psychological perspectives, such as those of Piaget (1965) and Maturana \& Varela (1994): According to them, Simondon recognizes that individuation in organic forms results in differentiation from the surroundings, which is relative to the historical relations established between them. Therefore, integration and differentiation are not permanent, even when some equilibrium is possible.

Moreover, as a systems thinker, Simondon does not consider the emergence of living individuals ${ }^{3}$ as well as the emergence of non-living things as an exclusive product of a process of homeostasis. The equilibrium of living beings is the result of a coupling with that which is different: in some way, the world is an implicit part of that emergence. In Maturana and Varela, (1994) this is called structural coupling: an organism depends on its interactions with what is outside; furthermore, its structure is shaped regarding the meaning that it gives to the world in its own activity ${ }^{4}$. Individuation suggests a process as long as the existence, in which, to differentiate itself, the individual also means its surroundings. The same act of individuation creates the borders and meanings of what is outside. In other words, individuation in life is a dialectic process between that which constitutes and that which is constituted: "the living being finds in the world forms that structure the living; on the other hand,

3 For Simondon there is an essential difference between a physical individual (e.g., a crystal) and a living one. The physical individual has no interiority, its activity results in an eternal demarcation of its borders but without a notice of itself; on the contrary, the living individual has an interiority; the individuation happens inside itself; it is because of that interiority that the surroundings have a meaning.

4 Piaget (1965), one of the thinkers that influenced Maturana and Varela's work, provides one of my favorite examples of structural coupling. Piaget stressed that organisms are the product of a bunch of meaningful relations with their surroundings: For instance, the Lymnaea Stagnalis, a freshwater mollusk has a long-shaped body in calm waters and a contracted-shaped body in more troubled waters. While traditionally it was thought that the two shapes were two races of the same species, it was discovered that putting contracted-shaped exemplars in calm waters results in an off-spring with the same phenotype characteristics of the original exemplars of those waters (a long-shaped off-spring). With these results, Piaget thought about the interaction of the genotype with the surroundings; it seemed that the environment is profoundly involved in a phenotypic manifestation. I consider this to be in agreement with Simondon's idea of individuation as a process of constitutive activity, namely as an active structuration process concerning the coupling with the surroundings. 
the living shapes the world to make it appropriate to itself"5 (Simondon, 2013, p. 208). If what the world means depends on the vital interests of the organism, we could identify Simondon's concept of individuation as a kind of immanent teleology that determines the organization and the coupling of a living individual with its surroundings. Individuation -as the movement towards an individual emergence- pulls integration among the parts of the system and differentiation of those things outside the internal processes (Simondon, 2009). It is an immanent teleology because there is no external law governing structuration; rather it is governed by the process of becoming an individual itself. Such a concept of individuation has similarities to the process of autopoiesis ${ }^{6}$ described by Maturana and Varela (1994): Like autopoiesis, individuation is an inner force (a force of the structure) pulling the balance between the individual and the surroundings and the structuration of living forms, in defiance of entropy. And, similarly to Maturana and Varela, for Simondon identity emerges from individuation, even though is not the end of that process. Rather, identity is only one of the phases of individuation, a phase that emerges in the permanent modification of an organism's structure in its relation to its surroundings. Previous to the individual, there is a process by which individuation occurs.

Information, transduction, and metastability replace any substantialization in the conformation of entities; although there are different modes of individualization in domains such as matter, life, spirit and society (Simondon, 2009), the principle of individuation is the same. In the end, the transductive relation, by which one structure that appears in one level of observation is extrapolated to another level, is the key to establishing a continuum from non-living to living; from to psychical to transindividual individuation. This individuation, as a form of differentiation and integration of entities, appears in all those levels, even though each level requires new ways of approaching it. For instance, psychical experience is a manifestation of individuation: "The

5 My translation. Original says: "L'être vivant trouve dans le monde des formes qui structurent le vivant ; le vivant, par ailleurs, donne forme au monde pour l'approprier à lui".

6 Autopoiesis responds to the question of what life is. For Maturana and Varela an organism is an autonomous entity that produces its own components and its own process, tending to differentiate itself from its surroundings; therefore, that self-production results in a system with a particular identity. 
psychic is the continuation of the vital individuation in a being that, in order to resolve its own problematic, must itself intervene as an element of the problem by its action, as a subject" (Simondon, 2009, p. 8).

However, it seems there is a phenomenon on the psychical level that must be understood; a phenomenon related to identity that seems to emerge in the midst of the individuation process: self-awareness. Self-awareness as the primal experience of subjectivity (Zahavi, 2005) would be a conscious level of individuation. In order to understand this, the physicalist discourse of thermodynamics, that explain individuation in organisms, should be replaced for a more phenomenological perspective. Therefore, the theory of individuation should accept a phenomenological point of view that apprehends self-experience as an emergent product inside the process of individuation. Following Simondon, this acceptance does not mean that there is an ontological gap between psychical and biological individuation: the continuum between these two levels is an important contribution of Simondon's theory.

\section{Some previous ideas on psychical individuation}

Initially, Simondon recognize differences between individuation at different levels. First, the biological is the "theater of individuation" (Simondon, 2009, p. 7): contrary to the non-biological forms, individuation of the living it is not determined by the formation of an individual; rather, is determined by the process of integration and differentiation. Second, while some metastability is required at the level of organic beings, stability in psychical life seems even less urgent and less permanent. On the other hand, organic bodies are defined by self-referential processes: affections such as pleasure and pain says something to the body -in informational terms-, and then mechanistically drive actions -e.g pain triggers the reflex of avoiding the fire-. On the contrary, in psychical life affection and emotion are meaningful experiences of a meaningful world;

7 Author's emphasis. 
therefore, they are not only qualities of organic bodies but of living ones: bodies that give meaning to their worlds.

Connecting Simondon to a more phenomenological perspective, activity is constitutive: to live is to actively give meaning to the world, to the self and to others. There is no experience of self, otherness, and world without an underlying activity by which they gain their meanings. And these meanings are historical: subjectivities and worlds, as currently experienced, are sedimented products of continuous activity. Sedimentation is the process of establishing unities of meaning -in the form of habits- that remain as results of the constitutive activity. For instance, to see the world as contained by objects is a habit coming from historical experiences of the lived body with concrete objects; to conceive one of those objects as food is the result of a different habit that includes meanings related to the sense of taste. An apparently stable world, such as the world full of objects that follow laws and the world of people that behave in predictable ways are the product of that previous, and ongoing, sedimentation process (cf. Husserl, 1982). If those habits are related to the lived body that means that meanings are bodily dependent: for instance, pain and pleasure both are constituted and constitutive experiences. As a constitutive experience, pain in an injured leg affects the whole experience of a situation: because of the pain, a child experiences the particular surroundings in which the accident has occurred as unfriendly; and as a constituted experience, the same pain changes by the previous meanings of a situation: a baby feels the pain more intensely in front of a stranger than when his mother arrives. Moreover, that pain is involved in what I have called self-experience: as a lived body, that constituting body is a constituting self: in other words, to give meanings to the world is to constitute a self. Here, this self-experience is a mere correlate of the lived body.

In Simondon, the subjective experience of pain in relation to others means that psychical life is extrapolated into the transindividual. Pain in the leg depends on the social context in which it is signified; the baby's bonding with his mother had consequences on the way the baby experiences himself. Furthermore, the self-experience is transindividual too. Following Simondon, 
psyche emerges and projects itself into the world, in an ongoing process, because it has its roots in the here and now.

That projective experience of the psychical life explains the relation between perception and action through the integration of the affectiveemotional aspects. Perception and action are phenomena of life forms as part of the organic body experiences, but for Simondon, its connections with the constitutive activity (giving meaning to the world), makes them linked to psychical activity as well. In this way, affectivity is a transductive phenomenon from physical activity in biological forms to psychological experiences. In psychism, affectivity is part of the subjective experiences and not merely describable in terms of physiological reactions.

\section{Affection and emotion in psychical experiences}

In living structures, affectivity appears as a principle of organization: it is what organizes the coupling between perception and action as functions tending to relations with the environment. Following Simondon, the affective saliences of the information or intensité determines what appears in the perceptual field and how to act. Here, intensity is an informational principle determined more by the vital dynamism of the organism than by the quality or quantity of the transmitted signals. Simondon criticizes both associationist and Gestaltic views of perception, and he seems motivated by Merleau-Ponty (Garelli, 2013), according to whom what is perceived is neither a product of association of separated qualities nor a form emerging from decontextualized laws of perception. For Merleau-Ponty (2012) perception, viewed as a projection into the world, is not something that occurs in the organ of perception as a total apprehension of something external; it rather seems to occur in the betweenness ${ }^{8}$ of the organism as a whole and the world.

8 The Japanese philosopher Watsuji thought the betweenness or Aidagara as a "field of possibilities in which individuals co-exist, communicate, and construct different ways of understanding and relating to one another" (Krueger, 2018, p. 2). Although betweenness seems the place of social interactions, is also the space for subjective relations with the world (Krueger, 2018, p. 3), which is in accordance with MerleauPonty's ideas. Also Aidagara, using Simondon's terms, would be the space in which individuation occurs at the same time that the world is constituted. 
This betweenness is not a physical space but is a way of expressing the activity of being in the world whilst conserving an individuality. This perception implies that it is not about capturing a shape, but about inventing it: the subject has some responsibility for what it perceives. In Merleau-Ponty, to belong to the world (être au monde) (2012, p. 80) means that the body constitutes the world to which it belongs, at the same time that the world is shaping perception. That betweenness is operating in the action schema: in Simondon, the action schema is an organization depending on the relation of movement to a meaningful experience; it shows the relationship between action and perception. The deer appears to the lion, not as captured by the Law of Pagnanz (as the Gestalt's Law of "good form"), but by the lion's vital projection -through hunger- to its prey, which is what makes the visual signals appear with a given intensity. Furthermore, for Simondon there is an affective connection between the lion and the deer, based on affective memory, which makes the prey emerge in the experience of the hungry animal.

In psychical life, affection is an organizing principle of the perceptive activity because interiorizes the outer world: it determines what is perceived in relation to intensity -in relation to what is vital-. On the other hand, emotion takes notice of the inner life and brings it to the world: while affection starts in the world, emotion starts in the inner life. Action, which at first sight seems pure mechanical exteriority -pure reflex reaction to fixed stimulus-, is organized by emotions to the extent that integrates action units with what is perceived, taking action to a new level of organization. In this regard, the coupling of affection and emotion makes sense: in psychical life, they cannot be separated. While affection organizes perception and action in regards to the world (in regards to how the world it is shown), emotion is what makes that experience a self-experience.

This coupling between action and perception through affection and emotion could be seen as the primary connection between Simondon's work and phenomenology: exploring the transition between what is simply physical individuation and conscious life (a life in which a self and a world are given in a first-person perspective). It is remarkable that Simondon, writing in 1958, gives emotion and affection a role that is only beginning to be recognized in 
contemporary phenomenology (cf. Colombetti, 2014; 2016; 2017): as the link between an enactive ${ }^{9}$ experience with a phenomenological one. The firstperson experience is the result of a coupling among action, perception and the affective life; affective life differentiates between affection as corresponding to the way the world is given and emotion as corresponding to the way the inner life is pulled towards the world.

So far, I have attempted a brief introduction to Simondon's idea of individuation that gives some elements to explore individuation in phenomenological terms. In the following chapter, I will connect Simondon's ideas on the coupling between perception and action, and affection and emotion from a more phenomenological perspective of the living body. I will posit that an ontogenetic perspective based on individuation as an organizing principle is the key to understanding constitutive activities in which a self, the world and others emerge.

\section{Individuation and the comprehension of the constitutive experience}

\section{Subconsciousness as the experience of a lived body}

In a phenomenological view of individuation, psychical life is a continuous constitution of a self-experience at the same time that the outer world is constituted. Furthermore, inner and outer experiences affects each other: an inner experience, for example, a lion's hunger for deer's meat, makes salient the shape of the deer amongst other things in the forest. However, hunger is also the result of the organism's coupling with the outer world; in sum, it is the result of coupling affections related to physical experiences (the primary hunger) with actions. The "hunger for meat" is

9 For enactivism (cf. Thompson, 2010), cognition emerges from the coupling between action and perception in a concrete environment. Meaning is not given to a passive organism, but it is the product of the situated activity in which that organism also emerges. Enactivism seems very close to Simondon's idea of information as emerging in the process of individuation, in which the pre-individual is actively integrating and differenciatinng itself from what is outside. 
construed in the previous experiences with an exteriority: hunger for meat is an historical experience.

Simondon realizes this experience in which self and world emerge, depends on emotion as the link between pure corporeality (hunger) and consciousness. As mentioned before, emotion pulls towards a consciousness of interiority, and in connection with a given action, brings the intentionality of the action to consciousness. However, before world and self are present to a consciousness, vitality remaining at the level of affection and emotion are neither cognitive and completely explicit nor merely organic and completely implicit: "Therefore, the intimacy of the individual should not be seen at the level of the pure consciousness or the organic unconsciousness, but rather of the affective-emotional subconsciousness"10 (2013, p. 242).

How to describe such subconsciousness which is neither pure consciousness nor the organic unconsciousness? In phenomenology, such subconsciousness would be an experience of the body that constitutes, contrary to the body as an organic structure. Hunger for meat is ultimately the result of a body that constitutes its own world rather than a body that moves mechanically. That constituting body is what Husserl (1989, pp. 151-170) called lived body: connecting Simondon with phenomenology, what he called a subconscious level is a pre-reflective level in the constituting experience of a lived body: namely, the implicit, tacit experience of consciousness. Therefore, I considered that what is in a subconscious level in Simondon could be seen, in terms of phenomenology, as a pre-reflective experience; and what Simondon understood as a conscious experience is what in phenomenology is called a reflexive level of consciousness.

Pre-reflective and reflective manifestations of consciousness are rooted in the idea of the lived body. Husserl distinguished between Leib and Körper, the lived body and the organic one: Körper as the material body is the object of anatomical and biological studies, and its structure corresponds to the individuation of living forms, according to Simondon (2013). On the

10 My translation. Original says: "L'intimité de l'individu ne devrait donc pas être recherchée au niveau de la conscience pure ou de l'inconscience organique, mais bien de la subconscience affectivo-émotive". 
contrary, Leib is the living and lived body, the body that constitutes worlds. As in Simondon, the activity of this body is based on the more pre-reflective experience, thus whatever reflective experience we have of this body is based on such more basic and bodily pre-consciousness.

Previous to reflective activity (or previous to the life of consciousness, in Simondon's terms), what Simondon called subconsciousness works on the level of the affective and emotional experience, which in phenomenology is part of the more basic experiences of the lived body. Among those basic experiences are also perceptual, motor and kinesthetic experiences (cf. SheetsJohnstone, 2011), all of these experiences are combined with affection and emotion to constituting the world. For example, the mathematical operation $2+2=4$ appears without a doubt (as apodictically evident) because of such constitutive activity with a history of learning to count with our fingers. This constitutive activity also accords with an ontogenetic perspective, as offered by developmental psychologists (cf. Piaget, 1955), according to which the first way in which the world appears is through sensory-motor activity.

According to Piaget (1955), the obvious character of addition has a previous step in the universal notion of object permanence, the experience of objects as discrete entities. Before that, at the beginning of life, there is no experience of objects; objects are the result of a historical and individual process in which the baby undertook a process of acting and perceiving his particular world: for example, the coordination between eye and hand. The latter conceptualization of the notion of object permanence is the result of a transductive process in which the sensory-motor experience on objects became a psychical notion. From a psychological perspective which radicalizes Piaget's (cf. Thelen \& Smith, 1994), if object permanence has to do with coordinating gaze and hand, it also has to do with the degree of body fat in the arms. In the end, that fat would affect the arm movements, and therefore, would affect the ability to reach objects to a lesser or a greater extent.

According to Thelen and Smith (1994) body fat affects the development of motor coordination and, later on, is related to delays in the cognitive development of the notion of permanence. As I said before, phenomenologists are only recently (Colombetti, 2016; 2017) taking the idea of emotional 
experiences as involved in these pre-reflective experiences seriously; therefore, we could think about the role of affection for the sedimentation of habits from which objects are given as differentiable entities. For instance, a constructionist point of view in which sociality is at the core of the formation of higher mental functions (cf. Vygotsky, 1981), could be helpful to understand the relationship between an affective atmosphere (as a social resonance in which the teacher and the child are involved) and the constitutive experiences that have appeared more as sensory-motor related.

Following the principles of constitution based on a pre-reflective view of subconsciousness, individuation also has to do with the fat, muscles and bones involved in actions such as reaching, crawling and jumping, in as much as these are part of integrating experiences as self-experiences. From this perspective, the world is not something different from the activity of the pre-reflective self: ultimately, self and world emerge in that activity. This is historical even though the original emergence of a world and a self is not explicitly given: I have no awareness of the way the world was given to me when I was a toddler, and of the constitutive processes in which the self and the world which I am experiencing now emerged. However, that history underlies, in a pre-reflective form, what is explicitly or reflectively given right now (cf. Husserl, 1975).

On the other hand, if pre-reflective life underlies what is given to me as the world and as a self, it is because that experience summarizes the history of sedimentations, as the remains of constitutive activity (cf. Husserl, 1989). While here individuation is the same constitutive activity, an individual is the result of a sedimentation process of a self-appearing as different from the world. However, according to Simondon, Husserl's sedimentation, as the way the world is given to us, is not the end of a constitutive activity, but rather a phase of it.

Transduction, in Simondon, is better understood as the historical process of phenomenological sedimentation. If transduction is the transmission of information among structures and different levels (cf. Simondon, 2009), the world reflectively experienced as apodictically evident (as real) would be the result of a transduction of what occurs in an implicit, pre-reflective experience. Therefore, genetic phenomenology (which reveals the constitutive, prereflective structures of what is evident to the consciousness) would inquire into 
those transductive experiences. In what follows, I will posit that Simondon's theory also opens some questions regarding ontogenesis in phenomenology. Here ontogenesis would be a discovery of the historical individuation; it would not only be the field of what underlines the reflective world but also of the historical roots in which the pre-reflective experience has evolved.

\section{Individuation and the individual: From activity to sedimentation}

In Simondon, individuation is compatible with a phenomenological perspective, which inquiries into the primal experience of a self. If individuation occurs as a process of integration and differentiation of the organism with the world, it means individuation is in some way contemporary (at least in its physical manifestation) with the constitution of a self that comes with the constitutive activity of the world and others.

Subjectivity can be seen from two different perspectives: the first, around genetic phenomenology, inquiries into the pre-reflective experience of a self that is present in every conscious experience. Here, the phenomenologist finds "a hidden subjectivity -hidden because it is not capable of being exhibited as present [aktuell] in reflection in its intentional activity but can only be indicated by the sedimentations left by this activity in the pregiven world" (Husserl, 1975 , p. 48). As a subjectivity is in relation with a permanent constitutive activity, the experience of a self is more an experience of apparent stability than an actual stable phenomenon. In terms of individuation, the subjective experience of individuality could be seen as a phenomenal experience of stabilization based on a continuous, never ending individuation process.

In a genetic approach, subjectivity based on the lived body is related, at least in Merleau-Ponty, with a body schema; an experience of the body as the summary of the possibilities of action within the constituted world: Husserl's "I cans" (2001, p. 51). When I am riding a bike, for instance, I am not reflectively aware of the position of my body; there, the road is the aboutness of my conscious experience. However, the transparency of my body 
indicates its constitutive activity: Because the body is operating as the center of experiences (as a "zero point", following Merleau-Ponty, 2012) it is not present as part of the experience. Although I can reflectively discern how every part of my body participates of the whole experience related with an acquired habit, the very act of noticing pulls me out of the flow of experience. When I notice how my body participates in swimming, I have ceased to be immersed in the experience of my body fluidly moving in the water.

Genetic phenomenology and individuation, seen as a subconscious phenomenon, describe self-experience and inquires about the fundamental reasons why self and world are given in such and such a way, even though it seems the subject does not have any agency over what appears to it. The cup appears in front of me as a tridimensional thing with shape and color, and those properties seem neither related with my activity nor my affections to the object; the cup appears as evident and in a world that appears as separate from myself. Although the subject experiences that passivity in relation with what appears, for a phenomenological perspective, as for individuation, the thing appearing in the visual field is the result of a sedimented history of active constitutions.

In Husserl, sedimentation is what remains after a synthetic activity in which separated experiences (sensory-motor, but also kinesthetic and affective) are organized in a meaning given through the same activity. In this case sedimentation is the habit as a way of capturing the world's meanings. It is the result of the activity of making sense of the world, which affects the way we perceive and act with it. Each encounter with an object affects sedimentation, from the baby that holds a cup for the first time, to the adult that is using a cup without a handle, and therefore is adjusting, through the changes on sensory-motor programs, the particular ways cups appears in the future. Ergo, sedimentation is an historical experience of the lived body in relation to the world.

Thus, Husserl (1975) recognizes passivity -as the world appearing as something stable and evident- does not imply inactivity, for a synthetic activity precedes and underlines what is given. Precedes, because the cup as something evident is the result of the sedimentation of an ontogenetic process. And underlines, because the current cup calls me (i.e, to my bodily self) to some intentional relationship with it (Husserl, 2001): when I am thirsty, my body is 
projected to the cup in a way that gives notice of the connection between the activity of reaching the cup and the thing that appears to that activity. I am not aware of each one of my movements and the tridimensional characteristics of the cup; however, this knowledge is operating in my movement. This link between an object and the activity of the living body shows the synthetic activity, in which an object has emerged by virtue of movement and concomitant kinesthetic experience in which the cup is perceived as a figure.

The second way to understand subjectivity is through an inquiry into the primal constitutive activities in which a world, a self and others emerge (cf. Sheets-Johnstone, 2011). A constitutive activity is an ontogenetic process related to the history of the individual: following Simondon, the process of individuation is accompanied by changes in the way oneself and the world are experienced in every step of life. Those changes are related with, along with process of sedimentation, perceptual-motoric changes occurring during evolution: for instance, the way the cup appears to the baby changes with the emergence of the eye-mouth coordination (Piaget, 1965). A methodological problem emerges because, from the first-person perspective of the phenomenologist, it is not possible to have a direct experience of the subjectivity in the first years of life. Then, a constructive work appears as a tool for understanding historicity in the constitutive activities. This phenomenology is defined as a "constructive discovery" (Walton, 2008) and uses the findings and observations of developmental psychology as "transcendental clues" (Sheets-Johnstone, 2011) alongside with first-person intuitions (for instance, the experience of a self) to reconstructing the path that starts with the first experience of the world -as it emerges in the womb- and continues with the current experience of a self and a world as two different entities. This methodology of inquiring into primal constitutive experiences is called by Sheets-Johnstone (2011, p. 193) a constructive phenomenology ${ }^{11}$.

11 It is important to highlight that this constructive phenomenology is not the same as Eugen Fink's $(1995 \$ 7)$. While he understood this phenomenology as a method for the transcendental onlooker to capture consciousness as a whole, which involves catching experiences that are not intuitively given (i.e. what is relative to natality and experiences close to death), Sheets-Johnstone understands constructive phenomenology as a way to capture the kinetic/kinesthetic, perceptual and affective roots of the way we currently experience our world. 
In Simondon, the transductive phenomenon explains that process of constitutive activity as it appears in different stages of the psychical individuation. Transduction is an operation "by which an activity propagates itself from one element to the next, within a given domain, and founds this propagation on a structuration of the domain that is realized from place to place an operation in which each area of the constituted structure serves as the principle and the model for the next area" (Simondon, 2009, p. 11). While self-experience, the world and others appear with apparent stability; in transduction, that stability is just a metastability, a transient phase of the individuation process in which every constitutive experience is modifying the whole domain in which it has some power. For instance, the emergence of the eye-hand coordination is not only a new perceptual-motoric ability but a way in which particular cups, bottles, and balls appear -the way they are constituted-; with those constitutions also the experience of the self as agent and of the whole surrounding world change, even though it seems not reflectively noticed.

What appears as the primal experience of psychical life is what SheetsJohnstone has understood as mere animation: "We come into the world already moving" (Sheets-Johnstone, 2011). Following Sheets-Johnstone, a Husserlian author that posits the experience of movement as the origin of constitutive activity, we could say that a world emerges in the first experience of coordination of the hand with the mouth, in which the fetus sucks its thumb for the first time. This could be the first tactile, three-dimensional experience and the first experience of the body that touches and is touched. Here, a world and a kinetic/kinesthetic and tactic self has emerged. After that first experience, the finger calls the movements of the mouth; the first habit will be that projection of the mouth to its first object. A path of individuation is also included in that experience: integration and differentiation is built up in the days, months and subsequent years. When we trace back our steps, we go back to the historicity of sedimentation, and there, we find the primordial fact that above all we are animated entities, like Sheets-Johnstone (2011) proposes. 


\section{Animation and individuation}

In the previous chapter, I discussed the relation between individuation as subconsciousness in Simondon and the pre-reflective experience in phenomenology. I related those concepts in terms of the experience of a lived body which through movement gives meaning to the world. Until here, all this seem linked to a sensory-motor body. Now, it should be introduced the coupling between that sensory motor body and an affective-emotional experience; a coupling that, in Simondon, is a main characteristic of the subconscious life, and which explains the continuity between organic and psychical individuation. Whereas phenomenology studies constitutive experiences through a conceptualization of the living body, it seems to miss the affective component that is involved in the corporeal relation to the world, and which, in my reading, is one of the contributions of Simondon's idea of psychical individuation.

Contemporary authors recognize the role of affection in a phenomenological approach. Colombetti (2014), for instance, stresses that the body is also affective, and even the way we navigate the world (perceptually and actively) has to do with this experience. The individual experiences along with the affective resonance with others and with the material world, configure an affective atmosphere as part of every situated constitutive activity: the emergence of a cup is a perceptual, motor and affective experience. For Colombetti, a phenomenology of a lived body should include affection as an essential part of what it means to be in a world: According to this theory, every experience has that affective component, and the history in which the world, others and subjectivity emerge is also a history of sedimented affections.

Before Colombetti, Simondon gave affection and emotion a primary role in individuation. I already described individuation in psychical life, and the nature of affective-emotional experiences in that process. I posit that these affective-emotional experiences are compatible with a theory of animation according to Sheets-Johnstone, and that their role in constitutive activity can be found in the ontogenesis of animated forms, from the point of view of constructive phenomenology. 
Primal kinesthetic and sensory experiences are accompanied by affectiveemotional experiences from an early stage in development. To suck the finger is a pleasant experience in a fetus. Since the beginning, pleasure reinforces the activity of suction, that by that point is far from the original adaptive function of the reflex. If we follow Simondon's arguments, in these first stages pleasure will represent an internal experience according to which the finger appears as something to a forming organism through some repeated sensory-motor experiences of the mouth. In phenomenological terms, the experience of the finger as an object is sedimented and motivated through pleasure, along with the mouth, as a moving part of the body. An experience of a minimal self appears in the fetus can be tracked in this basic experience in which affective, perceptual, motoric and kinesthetic experiences converge in giving meanings to one's own body. According to Sheets-Johnstone (2011), this convergence summarizes the basic phenomenon of being animate.

Sheets-Johnstone (2011) points out that before birth we are already animate beings, so the world is given to us in our own kinesthetic and sensory experiences. What makes constitution possible is not the body but the movement: the possibility of movements is the basis of the Husserlian I cans. The constitutive experience that accompanies living movement is what differentiates the movement of a stone from that of animated forms. The movement of a crystal, non-biological individuation, is different to biological individuation in that in the last case every movement is making worlds and subjectivities. That would make the difference between individuation with a path dependency that follows physical laws (the case of non-living beings) and permanent, self-referred individuation.

Primal animate experiences appear by kicking, sucking, rotating and pushing. At birth, these activities add new ones, which include the new world with which the baby is interacting. It should be emphasized that, in SheetsJohnstone, all biological movement is constitutive or accompanies a constitution insofar as it is part of existence. This means that there is no distinction between intentional and unintentional movements in relation to constitutive activity (cf. this distinction in philosophy of mind, Hanna and Maiese, 2009) because in animation, a movement, even if involuntary, involves sensory and kinesthetic 
experiences, by virtue of which even a bodily subjectivity is being constituted: to move implies, in its most minimal forms, a self-giving.

This idea of self-experience goes in accordance with studies in developmental psychology, in which one-month-old babies recognized their own-movements versus those of another (Rovee-Collier, 1999). Also, in the spasmodic movements of the baby there are kinesthetic experiences; for instance, Gallagher (2000) used studies with neonates and fetuses to investigate the emergence of a body schema that would be contemporary to the first organized movements.

In a first-person look at the experience of the initial stages of life there is no a formed subjectivity. In a non-subject experience, there are mere kinesthetic and affective experiences of resistance, of being pulled to, of being contracted, of turning around, of sucking and of having affective resonance with others, and all the possible ways in which kinesthetic, perceptual and affectiveemotional experiences inform about our own movements and some properties of the world attached to those movements. Subjectivity also emerges through these experiences.

For instance, let us think of a primordial experience: kicking. In kicking the fetal body is projected towards the world, the uterus; therefore, the uterus appears as resistance for the first time. Fetal movements are not random and mechanical as there is evidence that they depend on internal conditions. Kicking is associated with the baby's level of arousal (cf. Gallagher, 2000), so this first encounter already indicates an affective-emotional connection between the movement and what it encounters, the resistance to the movements themselves. For example, kicking is a projective experience of pleasure that usually appears as a response to the mother's voice.

The uterus appears in that pleasant projection as something opposed to the fetus's experience of its own body understood as a minimal experience of a self (which, as in the example of sucking the finger, is constituted in the affective, kinesthetic, motoric and perceptual experiences related to the emergence of a world). Just as the deer appears to the lion's visual projection in relation to hunger, in primordial animation the uterus becomes present in the pleasurable movement of that bodily self. According to Simondon, the 
projection to the world in the kicking is pulled by the emotion; therefore, resistance has to do with the force of the movement as given in an emotional experience. In other words, the world and even the self-experience of the fetus are given to its bodily consciousness in relation to an emotional response. And resistance is the way in which the world appears through animation.

This becomes the familiar world -at least until a new movement configuration emerges- as the result of the repetition of the experience of resistance in relation to the frequent pleasant projection. Going back to psychology (for example, Piaget, 1965), we can find proof that the world has emerged through kicking in the regularity of a scheme of action: what was an apparently random collection of movements is organized into a group of micromovements that anticipate that world. From the first person of the fetus, in repetition, the kicking stops being a simple pleasant projection: the uterus is the anticipated resistance. In other words, the pleasant projection of kicking is being affected by the world and this is the key to its sedimentation as a habit. The kick will no longer be the same as in the first experience, because now it brings forth the expectation of the encounter.

And this pleasant experience has been also constituted as an intercorporeal relation (Merleau-Ponty, 1992). The mother (who, by the way, caused the kicking through emotional resonance of the baby with her) and the fetus establish a first experience of inter-individuation in the resonance of each one's emotive-affective expressions. According to Simondon (2013), action and emotion are connected through the collective's individuation; in the case of the kicking, the mother gives some meaning to the baby's kick, which is transmitted to the fetus in an affective response to the felt movement in the uterus. The response of the fetus (the raising frequency of the kicking) establishes the sharing of the meaning. The dyadic relation between mother and child shows how the path that self-individuation builds in ontogenesis is in a connection with that intercorporeality; in phenomenological terms, the constitutive activity that underlines the world and the self is also a coconstitutive activity.

I find resistance as a starting point for a primordial world because it shows the coupling of affective-emotional experiences with tactile and kinesthetic 
senses, all operating in the same constitutive activity, in what seems initially a fortuitous encounter of the organic body with its surroundings. What follows next is that every movement relies on a world; that relying-on summarizes that process of constitution. Finally, relying-on involves that being attached, or attending to the call of the object in a specific way. While the object calls, the response to the call is configured by animation; what is given is associated with a certain affective, kinesthetic and sensorial configuration. This implies that even the call can be different depending on an alteration in that configuration: In a previous example, angriness can modify how a cup is perceived: it appears as something to express anger, as a something-to-be-smashed).

When the angry baby turns his head in the opposite direction of food, the world is presented in a different way; when the baby points his head towards food, his mouth is open to a part of the world. The figure and background are configured with the movement of the head, and its change ensures a different configuration. The rejection of the object and the approach to it depend on the fact that the animated being has also recognized its power over that which resists: it can decide how and when it has that world. This is just another example of the relevance of the historicity in phenomenology of the constitutive activity: the path traced involves an animate being who is in constant interaction with the surrounding world: the recesses, the returns, the advances are a product of a body imbibing itself in a territory and making decisions in its relationship with it.

\section{Conclusion}

Dan Zahavi (2005), one of the most prominent phenomenologists, stresses that, before a constituted subjectivity, we have a sense of the world as given in a first-person perspective. According to him, this first person givenness summarizes the experience of a primal self before the constitution of a subjectivity. In another work (Garavito, 2013), I posited that this firstperson experience is possible because, following Sheets-Johnstone (2011), the lived body is animated and mainly proprioceptive. This proprioception in an 
animated entity means that each sensory-motor and each affective experience involve a first person givenness through the proprioception attached to movements. To reach a cup includes a perceptual experience of the object, but also an experience of myself perceiving and moving: the way the object appears is the result of the coupling between perception and action that at the same time includes an experience of myself as perceiving and moving. In the fetus, resistance is lived as something outside, but in a close relation to the body: resistance is attached to the kinesthetic experience of kicking.

According to Simondon, individuation presents a problem that subjectivity resolves. That problem is the presentation of a world. In the organic level, the world is a stimulus, as an affective quality that corresponds to a mechanical reaction; in psychical life, the being extrapolates itself to the outside realizing that the outside is a world in which it has some kind of agency. Then, in that extrapolation the lived body finds itself as a subjectivity: In other words, with the world emerges the problem of subjectivity, and the world is what precisely appears as a concomitant result of the emergence of a subject.

On the other hand, subjectivity is an ontogenic product, the product of sedimentation of the constitutive activity. If we go backward, that sedimentation has its origin in the animated fetus that finds a world in its activity, and in the first resonant experiences with others, which makes the fetus to strengthen some emotional relations with the world. Here, we see subjectivity as an apparently stable experience that is based on the continuous flowing of individuation; a flowing related with a permanent constitutive activity. Subjectivity and alterity (as others and the world), therefore, are the phenomenological results of integration and differentiation as permanent activities that occurs in every level of individuation. 


\section{REFERENCES}

Bertalanffy, L. von (1968). General System theory: Foundations, Development, Applications. New York: George Braziller.

Colombetti, G. (2014). The Feeling Body: Affective Science Meets the Enactive Mind, Cambridge. Massachusetts: MIT Press.

Colombetti, G. (2016). Affective incorporation. In Simmons, J. \& Hackett, J. (Eds.), Phenomenology for the Twenty-First Century. New York: Palgrave Macmillan.

Colombetti, G. (2017). The embodied and situated nature of moods. Philosophia, 45(4), 1437-1451.

Fink, E. (1995). Sixth Cartesian meditation. EE.UU: Kluwer Academic Publishers.

Garavito, M. C. (2013). La animación en el origen de la conciencia de subjetividad, del mundo y de los otros: desde la fenomenología constructiva a la psicología del desarrollo (Magister Thesis). Bogotá: Universidad Nacional de Colombia.

Garelli, J. (2013). Preface. Introduction à la problématique de Gilbert Simondon. In Simondon, G. (Author), Lindividuation. À la lumière des notions de forme et d'information. Grenoble: Éditions Jérôme Millon, (9-20).

Gallagher, S. (2000). Phenomenological and experimental research on embodied experience. Working paper presented in Atelier phenomenologie et cognition. Phénoménologie et Cognition Research Group. Paris: CREA.

Hanna, R. \& Maiese, M. (2009). Embodied minds in action. EE.UU: Oxford University Press.

Husserl, E. (1975). Experience and Judgment. Investigations in a Genealogy of Logic. London: Routledge \& Kegan Paul. 
Husserl, E. (1982). Cartesian Meditations. The Netherlands: Martinus Nijhoff Publishers.

Husserl, E. (1989). Ideas Pertaining to a Pure Phenomenology and to a Phenomenological Philosophy: Second Book Studies in the Phenomenology of Constitution. EEUU: Springer.

Husserl, E. (2001). Analysis concerning Passive and Actives synthesis. The Netherlands: Kluwer Academic Publishers.

Maturana, H. y Varela, F. (1994). De máquinas y seres vivos. Autopoiesis: La organización de lo vivo (6th ed.). Buenos Aires: Lumen.

Merleau-Ponty, M. (1968). The visible and the invisible. Evanston: Northwestern University Press.

Merleau-Ponty, M. (1992). Signs. Evanston: Northwestern University Press.

Merleau-Ponty, M. (2012). Phenomenology of perception. New York: Routledge.

Piaget, J. (1955). The construction of reality in the child. London: Routledge and Kegan Paul.

Piaget, J. (1965). The origins of intelligence in children. New York: International Universities Press.

Rovee-Collier, C. (1999). The development of Infant Memory. Current directions in psychological science, 8(3), 80-85.

Sheets-Johnstone, M. (2011) The Primacy of Movement (Expanded 2nd ed., Vol. 82). Amsterdam/Philadelphia: John Benjamins Publishing Company.

Simondon, G. (2009). The position of the problem of ontogenesis. Parhesia, 7, 7-16.

Simondon, G. (2013). Lindividuation. À la l'umière des notions de forme et d'information. Grenoble: Éditions Jérôme Millon.

Thelen, E. y Smith, L. (1994). A dynamic systems approach to the development of cognition and action. EE. UU: MIT Press.

Thompson, E. (2010). Mind in life: Biology, phenomenology, and the sciences of mind. EE.UU: Harvard University Press.

Vygotsky, L. (1981). Genesis of higher mental functions. In Wertsch, J. V. (Ed.), The concept of activity in Soviet Psychology. New York: Sharpe, (144-188).

Walton, R. (2008). El tema del mundo y la pregunta por el método fenomenológico. En S. Eyzagurre (Ed.). Fenomenología y Hermenéutica. Actas del I Congreso 
On Individuation and Constitutive Activity: a View From the Philosophy of Gilbert Simondon and the Phenomenology

Internacional de Fenomenología y Hermenéutica. Caracas: Universidad Andrés Bello, (31-42).

Zahavi, D. (2005). Subjectivity and selfhood. Investigating the First-Person Perspective. EE.UU: Bradford Books. 
